\title{
Hydrogen Safety Issues Compared To Safety Issues with Methane and Propane
}

\author{
Michael A. Green \\ Lawrence Berkeley National Laboratory, Berkeley CA 94720, USA
}

August 2005

Presented at the 2005 Cryogenic Engineering Conference

Keystone Colorado, USA

29 August through 2 September 2005

Published in Advances in Cryogenic Engineering 51

* This work was performed at the Lawrence Berkeley National Laboratory with the support of the Office of High Energy Physics, United States Department of Energy under DOE contract DE-AC02-05CH11231. DOE funding for the US Neutrino Factory and Muon Collider Collaboration is also gratefully acknowledged. 


\title{
HYDROGEN SAFETY ISSUES COMPARED TO SAFETY ISSUES WITH METHANE AND PROPANE
}

\author{
M. A. Green \\ Lawrence Berkeley National Laboratory \\ Berkeley CA 94720, USA
}

\begin{abstract}
The hydrogen economy is not possible if the safety standards currently applied to liquid hydrogen and hydrogen gas by many laboratories are applied to devices that use either liquid or gaseous hydrogen. Methane and propane are commonly used by ordinary people without the special training. This report asks, "How is hydrogen different from flammable gasses that are commonly being used all over the world?" This report compares the properties of hydrogen, methane and propane and how these properties may relate to safety when they are used in both the liquid and gaseous state. Through such an analysis, sensible safety standards for the large-scale (or even small-scale) use of liquid and gaseous hydrogen systems can be developed. This paper is meant to promote discussion of issues related to hydrogen safety so that engineers designing equipment can factor sensible safety standards into their designs.
\end{abstract}

KEYWORDS: Flammable Gases and Liquids, $\mathrm{LH}_{2}$, and Hydrogen Safety

PACS: 47.15-x, 89.30Aa, 82.30Rs, and 06.60Wa

\section{INTRODUCTION}

The safety regulations for hydrogen (both in the liquid and gaseous state) compared to methane and propane were not always as burdensome as they are today at many of the government laboratories. Hydrogen was commonly used to light and heat houses during the hundred years between 1850 and 1950. Coal gas (or producer gas) was up to 50 percent hydrogen. The remaining components were carbon monoxide (30 to 40 percent) and other gasses. The flammability limits of coal gas are almost the same as for the hydrogen itself. The most dangerous part of using coal gas was carbon monoxide poisoning. As a result, a small amount of an agent that causes the stink of gas had to be added to the gas. Prior to 1937 hydrogen was used as a lifting agent for passenger carrying dirigibles. Hydrogen gas has been used as a cooling agent for very large generators since the 1930's.

What changed the safety regulations and the perception of safety regulators (particularly at the US physics laboratories)? The event that changed the perception of the public was the Hindenburg disaster at Lakehurst New Jersey in 1937. The Hindenburg burned and crashed, killing nearly half of the passengers who had flown from Berlin. (Most of the passengers who died fell or jumped from the Hindenburg.) The disaster that affected the thinking about liquid hydrogen in US laboratories was the explosion and fire that killed several people at the Cambridge Electron Accelerator in Cambridge Massachusetts in the 1960s. 
This paper will compare hydrogen with methane, and propane. It is hoped that the paper will separate some real dangers of hydrogen from the perceived dangers of hydrogen. This paper is not intended to be the end all paper on hydrogen safety. A comparison between hydrogen safety standards and those applied to methane and propane leads to a number of inconsistencies, particularly when one considers the fact that hydrogen may be less dangerous than either methane or propane.

This paper will show that safety standards that are commonly applied to systems with small amounts of liquid hydrogen or gaseous hydrogen may not make sense when applied to larger quantities of liquid or gaseous hydrogen. Safety committees often make blanket pronouncements concerning hydrogen safety without thinking of the consequences. In the eyes of some safety committees, not allowing the use hydrogen is the only safe course of action. This is like saying that physics will be safe as long as no one does any experiments.

\section{PROPERTIES OF HYDROGEN, METHANE, AND PROPANE}

In TABLE 1, hydrogen is compared with methane and propane in terms of hazards that may damage equipment or endanger people. The list of hazards include 1) rapid expansion from liquid to gas, 2) material failure due to temperature embrittlement, 3) freezing of body parts due to temperature, 4) oxygen enrichment on the tank surface, 5) flammability or chemical explosion, 6) chemical embrittlement due to exposure, 7) asphyxiation (oxygen deprivation), and 8) the density of the gas relative to room temperature air. The hazards shown in TABLE 1 are directly related to the physical properties of the three gasses. (The author does not consider propane to be a cryogenic gas, because its 1 atm liquefaction temperature is above that of air gasses. In many ways propane behaves like a cryogenic gas.)

The chemical and cryogenic properties of the three gasses are presented in TABLE 2 and TABLE 3. TABLE 2 compares the chemical properties that relate to flammability for hydrogen, methane, and propane [1]. The stoichiometric burning of the three gasses in air is given as follows;

$$
\begin{gathered}
2 \mathrm{H}_{2}+\mathrm{O}_{2}+3.76 \mathrm{~N}_{2}=2 \mathrm{H}_{2} \mathrm{O}+3.76 \mathrm{~N}_{2} \\
\mathrm{CH}_{4}+2 \mathrm{O}_{2}+7.52 \mathrm{~N}_{2}=\mathrm{CO}_{2}+2 \mathrm{H}_{2} \mathrm{O}+7.52 \mathrm{~N}_{2} \\
\mathrm{C}_{3} \mathrm{H}_{8}+5 \mathrm{O}_{2}+18.8 \mathrm{~N}_{2}=3 \mathrm{CO}_{2}+4 \mathrm{H}_{2} \mathrm{O}+18.8 \mathrm{~N}_{2}
\end{gathered}
$$

Note: the equations above neglect argon, carbon dioxide, and the trace gasses that are present in air. These gasses have little effect on the chemical process. The stoichiometric burning of the gasses in oxygen can be represented by the equations above with the nitrogen taken out.

TABLE 3 presents the cryogenic properties of the hydrogen, methane and propane [2]. For comparison, the cryogenic properties of helium [3], nitrogen [2], and oxygen [2] are also included in TABLE 3. (Note: under the usual definition of a cryogenic fluid, propane isn't one.) Helium and nitrogen were included because they are well understood cryogenic fluids commonly used in physics experiments. The properties of oxygen are given because it is the oxidizing agent for all three of the flammable gases given in the table. Liquid air has properties that are between those of oxygen and nitrogen.

TABLE 1. A list of safety hazards associated with liquid and gaseous hydrogen, methane and propane.

\begin{tabular}{lccc}
\hline \multicolumn{1}{c}{ Potential Safety Hazard } & $\mathrm{H}_{2}$ & $\mathrm{CH}_{4}$ & $\mathrm{C}_{3} \mathrm{H}_{8}$ \\
\hline Large liquid to gas expansion ratio & Yes & Yes & Yes \\
Cryogenic embrittlement of materials & Yes & Yes & Sometimes \\
Freezing of body parts (human) & Yes & Yes & Maybe \\
Flammability and chemical explosion & Yes & Yes & Yes \\
Chemical embrittlement of materials & Yes & No & No \\
Oxygen enrichment due to temperature & Yes & No & No \\
Asphyxiation (oxygen deprivation) & Yes & Yes & Yes \\
Is the gas heavier than 300 K air? & No & Sometimes & Always \\
\hline
\end{tabular}


TABLE 2. The combustion characteristics of hydrogen, methane, and propane in air and pure oxygen.

\begin{tabular}{lccc}
\hline \multicolumn{1}{c}{ Parameter } & $\mathbf{H}_{\mathbf{2}}$ & $\mathbf{C H}_{\mathbf{4}}$ & $\mathbf{C}_{\mathbf{3}} \mathbf{H}_{\mathbf{8}}$ \\
\hline Flammability limits in air (\%) & $4.0-74.2$ & $5.0-15.0$ & $2.1-9.4$ \\
Ignition temperature in air (K) & $\sim 855$ & $\sim 925$ & $\sim 770$ \\
Ignition energy @ STP (J/cc) & $\sim 0.74$ & $\sim 0.97$ & $\sim 0.76$ \\
Stoichiometric flame temperature in air (K) & $\sim 2580$ & $\sim 2340$ & $\sim 2390$ \\
Flammability Limits in Pure $\mathrm{O}_{2}(\%)$ & $4.6-93.9$ & $5.4-59.2$ & $2.4-61.1$ \\
Heat of combustion (kJ g ${ }^{-1}$ ) & 135.4 & 52.8 & 40.3 \\
Liquid heat of combustion (MJ per liter) & 9.59 & 22.29 & 23.56 \\
Gas heat of combustion (MJ $\left.\mathrm{m}^{-3} @ \mathrm{STP}\right)$ & 12.09 & 37.70 & 93.48 \\
Peak combustion pressure ratio Air & $\sim 8.8$ & $\sim 8.0$ & $\sim 8.2$ \\
Lower $\mathrm{O}_{2}$ combustion limit in $\mathrm{O}_{2}-\mathrm{N}_{2}$ mix $(\%)$ & $\sim 3.2$ & $\sim 4.0$ & $\sim 4.5$ \\
Temp when gas is heavier than RT air $(\mathrm{K})$ & $\sim 21$ & $\sim 162$ & $\sim 444$ \\
\hline
\end{tabular}

The flammability limits shown in TABLE 2 do not tell the whole story. FIGURE 1 and FIGURE 2 show the flammability limits for hydrogen and methane as a function fuel content expressed as percent of the fuel in a fuel-oxidizer mixture and the oxygen content of the oxidizer (a mixture of oxygen and nitrogen). The flammability limits given apply at STP $(\mathrm{STP}=293.16 \mathrm{~K}$ and $0.1013 \mathrm{MPa})$. The flammability limits change with temperature and pressure. At pressures below about $100 \mathrm{~Pa}$, there is no burning [4]. At pressures of $1500 \mathrm{~Pa}$ there may be burning, but an explosion is not a hazard [4].

TABLE 3. Various properties of the solid, liquid and gas for helium, nitrogen, oxygen, hydrogen, methane, and propane. Included in the table is the maximum heat flux into the liquid gas when the cryostat vacuum is broken or when the liquid gas spills into the cryostat vacuum vessel.

\begin{tabular}{|c|c|c|c|c|c|c|}
\hline Parameter & He & $\mathbf{N}_{2}$ & $\mathbf{O}_{2}$ & $\mathbf{H}_{2}$ & $\mathrm{CH}_{4}$ & $\mathbf{C}_{3} \mathbf{H}_{8}$ \\
\hline Triple point temperature $T_{t}(K)$ & $2.177^{\wedge}$ & 63.15 & 54.36 & $13.81^{*}$ & 90.69 & 91.46 \\
\hline Triple point pressure $\mathrm{P}_{\mathrm{t}}(\mathrm{kPa})$ & 5.04 & 12.46 & 0.146 & 7.04 & 11.70 & -ND- \\
\hline Triple point density $\square_{\square}\left(\mathrm{kg} \mathrm{m}^{-3}\right)$ & $129^{\wedge}$ & 870 & 1306 & $77.0 *$ & 451.5 & $\sim 670$ \\
\hline Heat of fusion @ Tt (J g-1) & -NA- & 25.3 & 13.7 & $59.5^{*}$ & 58.41 & 79.97 \\
\hline Boiling temp.Tb@1 bar (K) & 4.222 & 77.35 & 90.19 & $20.28^{*}$ & 111.67 & 230.46 \\
\hline Liquid density rl @ Tb (kg m-3) & 124.9 & 807 & 1141 & $70.8^{*}$ & 422.4 & 585.3 \\
\hline Gas density rg@ $\mathrm{Tb}$ (kg m-3) & 16.89 & 4.622 & 4.467 & $1.339^{*}$ & 1.816 & 2.497 \\
\hline Gas to liquid volume ratio at $\mathrm{Tb}$ & 7.395 & 175.6 & 255.4 & $52.87 *$ & 232.6 & 298.0 \\
\hline Gas V293 to Liquid Vb Ratio & 699.4 & 645.6 & 798.7 & 792.9 & 591.4 & 379.0 \\
\hline Liquid Cp@ Tb (J g-1 K-1) & 5.255 & 2.042 & 1.699 & $9.668^{*}$ & 3.481 & -ND- \\
\hline $\operatorname{Gas}_{\mathrm{p}} @ \mathrm{~T}_{\mathrm{b}}\left(\mathrm{J} \mathrm{g}^{-1} \mathrm{~K}^{-1}\right)$ & 9.144 & 1.341 & 0.980 & $12.24^{*}$ & 2.218 & 1.642 \\
\hline Heat of vaporization @ $\mathrm{T}_{\mathrm{b}}\left(\mathrm{J} \mathrm{g}^{-1}\right)$ & 20.7 & 198.8 & 213.1 & $445^{*}$ & 510.8 & 424.8 \\
\hline Heat flux for $\square \mathrm{T}=300-\mathrm{T}_{\mathrm{b}}\left(\mathrm{kWm}^{-2}\right)$ & $\sim 200$ & $\sim 27$ & $\sim 24$ & $\sim 93$ & $\sim 47$ & -NA- \\
\hline Broken vacuum heat flux $\left(\mathrm{kWm}^{-2}\right)$ & $\sim 35$ & $\sim 1.6$ & $\sim 0.35$ & $\sim 19$ & $\sim 0.31$ & -NA- \\
\hline Critical temperature $\mathrm{T}_{\mathrm{c}}(\mathrm{K})$ & 5.195 & 126.2 & 154.6 & 32.98 & 190.6 & 368.8 \\
\hline Critical pressure $\mathrm{P}_{\mathrm{c}}(\mathrm{MPa})$ & 0.228 & 3.39 & 5.04 & 1.29 & 4.59 & 4.36 \\
\hline Critical density $\square_{c}\left(\mathrm{~kg} \mathrm{~m}^{-3}\right)$ & 69.64 & 313 & 436 & 31.0 & 162.7 & $-\mathrm{ND}-$ \\
\hline
\end{tabular}

$\wedge$ The triple point for helium is the Lambda point where the gas and two liquid states coexist.

* This is for hydrogen in the para state. 


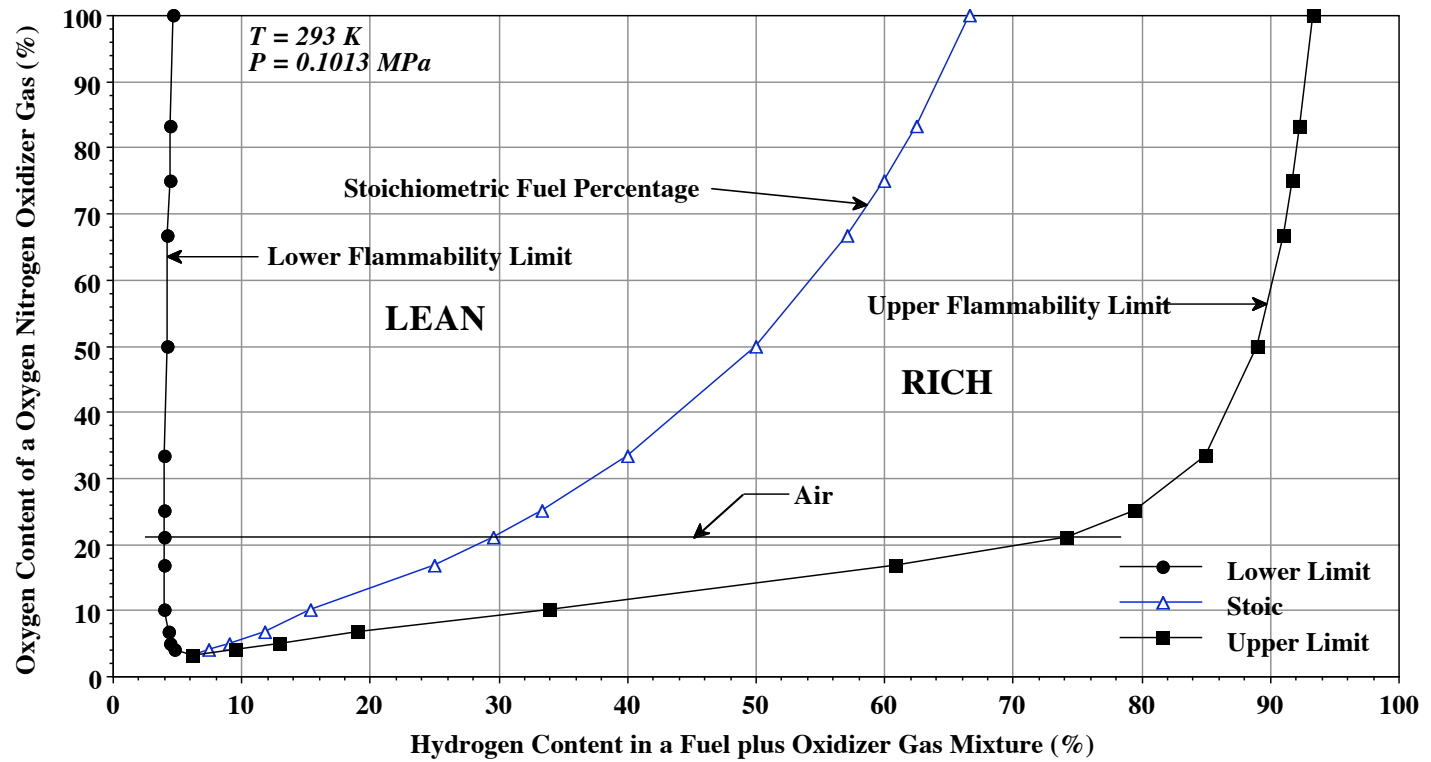

FIGURE 1. The flammability limits for hydrogen in an $\mathrm{O}_{2}-\mathrm{N}_{2}$ oxidizer gas mixture as function of the percentage of hydrogen in the fuel-oxidizer gas mixture and the percentage of oxygen in the $\mathrm{O}_{2}-\mathrm{N}_{2}$ mixture.

The flammability limits shown in FIGURE 1 and FIGURE 2 are the measured values for an oxidizer gas that is 100 percent and 21 percent oxygen (air). The other values for the flammability limits are calculated based on the energy needed to sustain the burning (the energy needed to raise the mixture to its ignition temperature). In the literature, the term flammability limit and explosive limit are often interchanged. The explosion limits are narrower than the flammability limits, because extra energy is needed for detonation to occur. When one compares FIGS. 1 and 2 and the data in TABLE 2, it is clear that the flammability limits for hydrogen are much broader than for methane or propane. The upper flammability limit is driven by stoichiometry. The upper flammability limit for $\mathrm{CO}$ and $\mathrm{H}_{2}$ are the same in air and pure $\mathrm{O}_{2}$. From the standpoint of safety, the upper flammability limit is usually less important than the lower flammability limit, because safety is often approached from the lower flammability limit end. Also important is the lower flammability limit based on oxygen content of the oxidizer (3.2 percent for $\mathrm{H}_{2}$ and 4 percent for $\mathrm{CH}_{4}$ ).

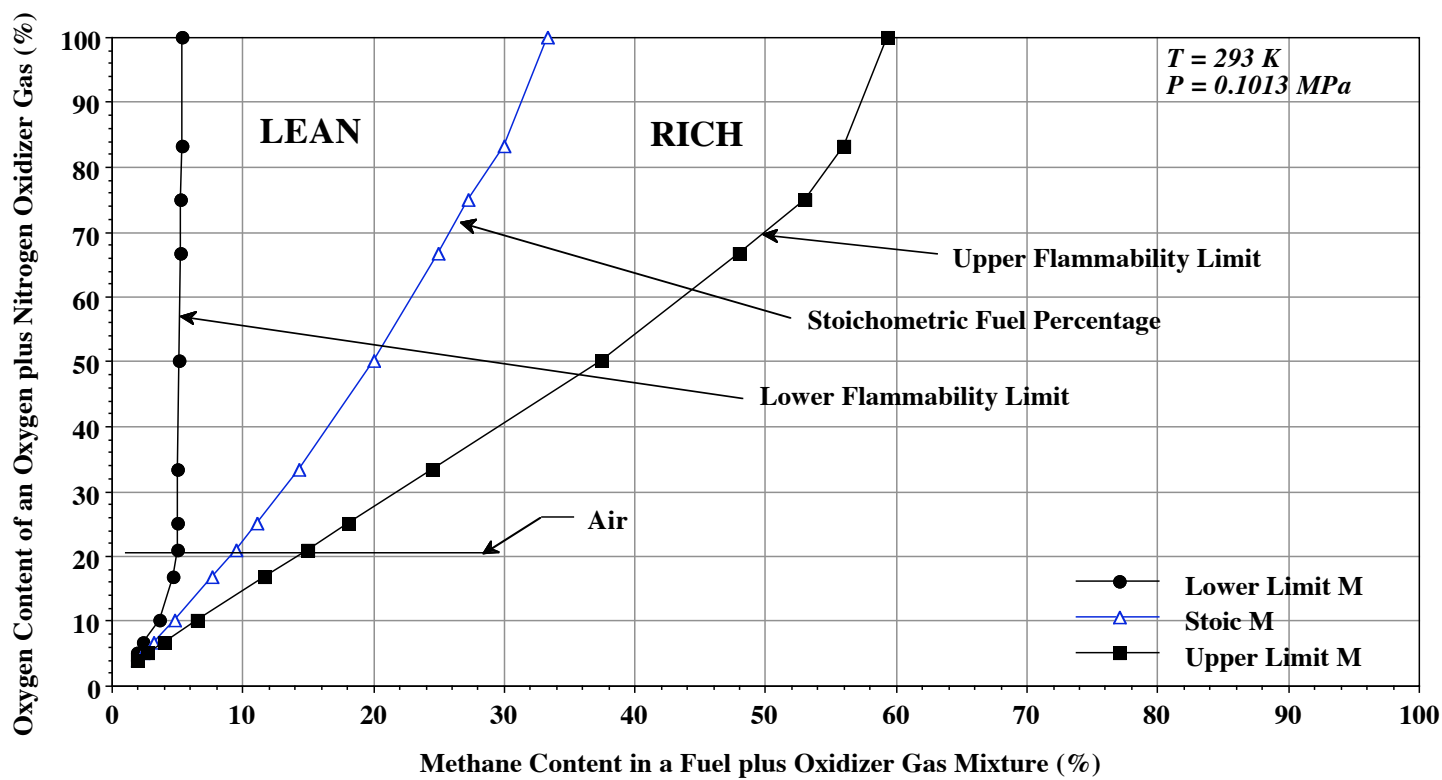

FIGURE 2. The flammability limits for methane in an $\mathrm{O}_{2}-\mathrm{N}_{2}$ oxidizer gas mixture as function of the percentage of methane in the fuel-oxidizer gas mixture and the percentage of oxygen in the $\mathrm{O}_{2}-\mathrm{N}_{2}$ mixture. 


\section{HYDROGEN SAFETY ISSUES FOR LIQUID AND GAS}

TABLES 2 and 3 contain enough data to develop reasonable safety strategies for hydrogen. When developing hydrogen safety strategies, it is useful to compare them with the safety strategies commonly used for methane and other flammable gasses. Specific safety requirements are imposed by some laboratories. Some of these regulations are discussed, but the laboratories shall remain nameless to protect the innocent.

The topics in this section include the following: 1) cryogenic and chemical embrittlement, 2 ) the design of liquid hydrogen vessels, and gas vessels, 3) design of the cryostat vacuum vessel (including oxygen enrichment), 4) thin window design, 5) the design of the hydrogen fill and vent systems, 6) the hydrogen zone and sensor location, and 7) other hazards. There may be other potential safety issues not discussed here. All of the safety issues that are relevant to the hydrogen device being built must be included in the safety documentation.

\section{Cryogenic and Chemical Embrittlement}

Cryogenic embrittlement is the key element in the selection of materials for any cryogenic device. The materials that can be safely used in a cryogenic system include some high nickel steels, invar and related materials, austenitic stainless steels, most aluminum alloys and most copper alloys. Cryostats for use at temperatures below $140 \mathrm{~K}$ are commonly made from austenitic stainless steels and aluminum for both the cryogen vessel and the vacuum vessel. Propane tanks are commonly made from steel with a temperature rating of $-50 \mathrm{C}$.

Propane and methane do not cause chemical embrittlement in the way hydrogen does. Hydrogen embrittlement is a function of pressure and the exposure time [5]. Fortunately, hydrogen embrittlement is not a problem with most of the materials used to fabricate cryogenic vessels [5]. Avoid the use of carbon steel and the nickel steels commonly used in methane vessels. The welds in 304 stainless vessels can be subject to embrittlement.

\section{The Design of the Cryogenic Vessel and Room Temperature Gas Vessels}

All cryogen vessels and attached gas vessels for a liquid-hydrogen, a liquid-methane, or a propane system must be designed in accordance with the applicable pressure vessel code for flammable gasses and liquids. The piping used to connect the cryogenic vessel to external gas vessels must be rated for carrying a flammable gas or liquid at the lowest temperature in the system. The hydrogen vessel must withstand a pressure that would make an attached thin window burst. At the point where a thin window is designed to burst (at room temperature), the stress in the metal in the rest of the vessel should be lower than the yield stress. Air leaks into a liquid-hydrogen vessel must be eliminated. The vessel must operate at a pressure above $0.11 \mathrm{MPa}$ or exposed warm gas pipes to the vessel must have an inert cover gas.

The cryogen vessel should be a welded vessel. Elastomer seals must not be used. Metal seals on pipes that are attached to the cryogen vessel must be approved for use with flammable cryogenic gasses and liquids or they must undergo a certification program that is approved by the safety committee. Any instrumentation used in the cryogen vessel must be certified (either by test or by a recognized agency) as usable with flammable fluids.

\section{The Design of the Room Temperature Cryostat Vacuum Vessels}

Propane tanks do not have vacuum vessels. Large liquid methane tanks may not have vacuum vessels either, because foam insulation is often used. Large methane vessels have a liquefier that re-liquefies the methane that is boiled off. Since there is no oxygen enrichment in the insulation, this is reasonable. Liquid hydrogen tanks nearly always have an insulating vacuum with MLI. Large NASA hydrogen vessels are an exception. An example is the space shuttle external hydrogen tank, which is foam insulated without a vacuum vessel. It is better to boil off extra hydrogen on the ground than to carry a vacuum vessel into space.

It can be argued that a hydrogen-cryostat vacuum vessel must be designed to the same standards as the cryogen vessel. The root of this argument is that in the event of a hydrogen leak into the vacuum vessel, the vacuum vessel becomes a flammable gas (or liquid) vessel. There are laboratories that use less stringent standards for the design of a cryostat vacuum vessel. This is not consistent, particularly if the vacuum vessel has thin windows in it. 
There is at least one laboratory that requires that the vacuum vessel for a hydrogen tank be 52 times larger than the hydrogen tank. The theory for this requirement is that the vacuum vessel can take all of the gas that is evaporated at $20 \mathrm{~K}$ without a pressure rise. One should ask the question, "Would one design a liquid helium vessel (helium has a very low heat of vaporization) or a liquid-nitrogen vessel (nitrogen expands over 150 times from liquid to gas at $77 \mathrm{~K}$ ) this way?" The answer is no. The premise behind this rule doesn't make sense, because one can design the vacuum vessel relief system to carry the hydrogen gas that will be produced by film boiling on the room temperature vessel walls. (See TABLE 3 [6] to [8].) The vacuum vessel must have relief devices that vent it into the hydrogen venting system.

Because the boiling temperature of liquid hydrogen is below the triple point temperature of all gasses (except $\mathrm{He}$ and $\mathrm{Ne}$ ), air gasses that leak into the vacuum vessel will freeze on the outer surface of the hydrogen container. (This can be a hazard even for a liquid helium tank.) A second worry is oxygen from the air combining with hydrogen in the vacuum vessel. For this to be a safety hazard, the following must occur: 1) air leaks into the cryostat vacuum vessel; 2) hydrogen leaks into the vacuum vessel; 3) the hydrogen vessel warms up to release oxygen; and 4) there is a source of ignition to ignite the mixture of hydrogen and air.

The reason that an air leak into a hydrogen cryostat vacuum vessel is considered to be a potential safety problem is that an air leak is undetectable. Even air leaks at the $10^{-3} \mathrm{~Pa} \mathrm{~m}^{3} \mathrm{~s}^{-1}$ level are cryo-pumped to the surface of the hydrogen vessel without a rise in pressure. On the other hand, a hydrogen leak is very detectable, because the vacuum in the cryostat rises. A cryostat vacuum of $0.1 \mathrm{~Pa}\left(10^{-3}\right.$ torr $)$ is enough to be measured and it is enough to spoil the performance of the MLI. At least one laboratory recommends that the vacuum vessel of a liquid hydrogen cryostat be blanketed with another vacuum or an inert gas. One does not have to go that far, provided the following steps are taken: 1) the vacuum vessel is welded closed by qualified welders (with no elastomer seals); 2) the hydrogen vessel is welded closed by qualified welders; and 3 ) there is no ignition source in the cryostat vacuum space.

\section{Thin Window Design}

Thin windows are commonly used in physics experiments. The laboratories that conduct such experiments often have their own standards that are applied to thin windows. In most physics experiments, the thin windows must be made from low- $Z$ material that has a low density. In addition the windows must be strong at room temperature and even stronger at cryogenic temperatures. The windows must not be subject to cryogenic or chemical embrittlement. Under theses standards, the use of beryllium or Mylar windows is precluded on most liquid hydrogen vessels. Beryllium windows may be used on a methane vessel.

Several laboratories have the following requirements for flammable-liquid thin windows; 1) The system must have a minimum working pressure of $0.17 \mathrm{MPa}$. 2) The minimum design burst pressure must be four times the system working pressure. A representative number of the thin windows (say 4 to 6 windows) must be burst at room temperature and all of the windows must burst at pressures above the minimum design burst pressure. At least one window must be burst at $77 \mathrm{~K}$ to verify that the $77-\mathrm{K}$ burst pressure is higher than the room temperature burst pressure. 3) The windows must not buckle at room temperature at an external pressure of $0.17 \mathrm{MPa}$. 4) The thin window and its seal must be vacuum leak tight. The usual standard of leak tightness is better than $10^{-9} \mathrm{~Pa} \mathrm{~m}^{3} \mathrm{~s}^{-1}$ for helium at room temperature at a pressure of $0.1 \mathrm{MPa}$ measured with a mass spectrometer leak detector. The design requirements given above are reasonable. Thin windows for a liquid hydrogen cryostat vacuum vessel should be designed to the same standards as the windows for a liquidhydrogen vessel, because when a window on the liquid-hydrogen vessel bursts or leaks, the vacuum vessel window become the primary safety window.

\section{The Design of the Hydrogen Fill and Hydrogen Vent Systems}

A survey by one laboratory revealed that most safety incidents with liquid hydrogen systems occur when the liquid hydrogen device is being filled or is being emptied. Most small liquid hydrogen devices are completely closed cycle with all of the hydrogen put in as a gas at room temperature. A refrigerator liquefies the hydrogen in the system. As the hydrogen is liquefied, the gas pressure goes down in the external storage tank. The concept of a closed cycle system is illustrated in FIGURE 3. 


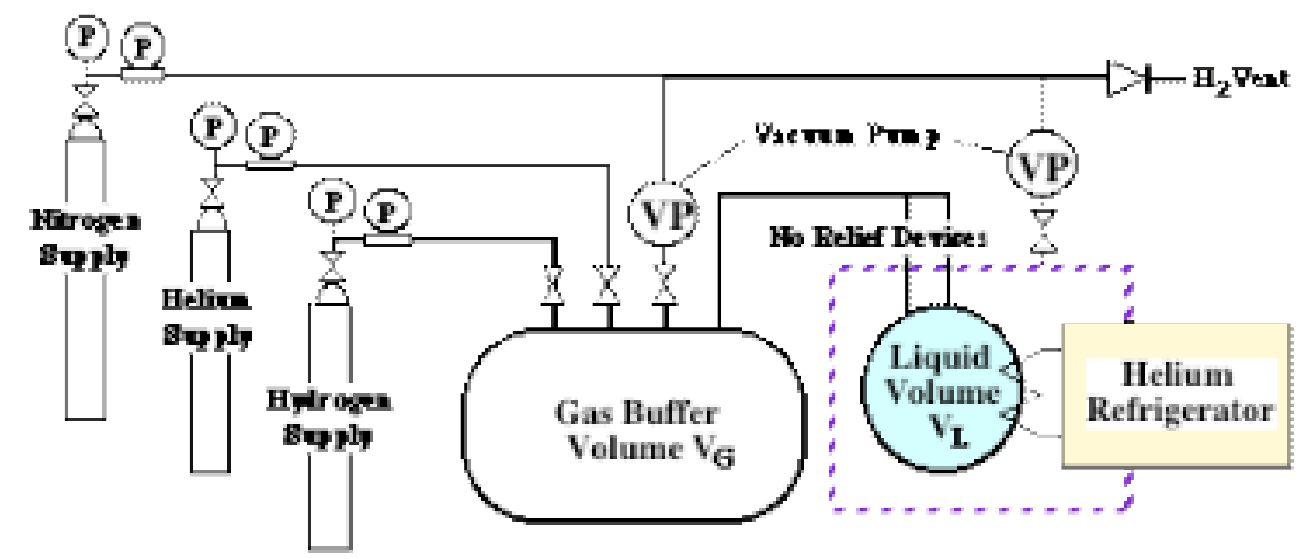

FIGURE 3. A schematic of a closed-cycle liquid-hydrogen system. The gas is stored in the buffer volume.

The size of the gas volume $\mathrm{V}_{\mathrm{G}}$ is a function of the liquid hydrogen volume $\mathrm{V}_{\mathrm{L}}$, the maximum allowable working pressure anywhere in the system $\mathrm{P}_{\mathrm{M}}$, the pressure when the liquid volume is filled $\mathrm{P}_{\mathrm{L}}\left(\mathrm{P}_{\mathrm{L}}=0.1013 \mathrm{MPa}\right)$, and $\mathrm{\square}\left(\mathrm{P}_{\mathrm{L}}\right)$ the volume ratio of gas at $293 \mathrm{~K}$ and the liquid. (From TABLE 3, $\square=793$ when $P_{L}=0.1013 \mathrm{MPa}$ ). The gas volume for a closedcycle hydrogen system can be estimated using the following expression;

$$
V_{G}=\frac{\square\left(P_{L}\right) \square\left(P_{M} / P_{L}\right)}{\left(P_{M} / P_{L}\right) \square 1} V_{L}
$$

From the equation above one can see that if $\mathrm{P}_{\mathrm{M}} / \mathrm{P}_{\mathrm{L}}$ is small the gas volume is large relative to the liquid volume. If the hydrogen system can be designed so that $\mathrm{P}_{\mathrm{M}}$ can be above the critical pressure, the gas volume relative to the liquid volume will be more manageable.

The passive system shown in FIG. 3 is safe. When there is a fault that results in a rapid boil-off, the gas volume takes up the hydrogen gas without venting, provided the pipes are sized correctly. Large systems (>10 liters) are often not made passive, because it would cost too much. An open system is one that is filled with gas from bottles or liquid from a tank. Systems where fuel is being supplied to a vehicle (the space shuttle) are by definition open systems. An intermediate system might use a hydride bed as a virtual gas volume. Gas can be supplied and be taken up by a hydride bed at its design rate, but no faster. Gas that must be vented faster than the hydride bed design rate must be vented to the outside world.

In any system, the vent must be designed correctly. Some of the things that one can do to design a safe vent system include the following; 1) the vent system should be flooded with an inert gas (helium, nitrogen or argon), 2) the vent must be designed to have a low pressure drop at the peak gas flow; 3) the vent system can be made explosion proof by using pipes thick enough to contain a pressure of $5 \mathrm{MPa}$ (The weakness may lie in the rest of the system.); and 4) the end of the vent pipe must be above the roof of the hydrogen system building. Some safety regulations may require that the hydrogen be burned off at the vent.

\section{The Hydrogen Zone and Sensor Location}

The hydrogen zone is defined as the zone where ignition sources are completely barred. The ignition sources include but are not restricted to; 1) flames or heating elements that go above the ignition temperature of the gas, 2) electrical sparking [9], 3) sources of static electricity than can cause sparking [10], and 4) improper tools. (About $0.02 \mathrm{~mJ}$ will ignite $\mathrm{H}_{2}$, $\mathrm{CH}_{4}$, and $\mathrm{C}_{3} \mathrm{H}_{8}$.) The definition of a hydrogen zone varies widely. European standards allow for a hydrogen zone to be restricted to the region under a hood over the hydrogen area. In the US, the hydrogen zone may include a whole building. This means that the building electrical system must be explosion proof and other sources of ignition must be eliminated.

Hydrogen sensors must be located above the hydrogen system because hydrogen will always rise. Sensors for propane must be below the device, because propane is always heavier than air. Methane can be lighter or heavier than air depending on its temperature. 


\section{Other Safety Issues}

Other safety issues include asphyxiation and freezing. Asphyxiation is not an issue as long as one is below the lower flammability limit. Asphyxiation may be an issue in locations where an inert cover gas is used to ensure that the oxygen content of the gas around the apparatus is lower than the lower limit for oxygen (about 3 percent). A well-designed hydrogen or methane system does not have any exposed pipes that are at cryogenic temperatures. The vent pipes may be cold enough to cause freezing after an emergency venting of the system. Propane systems often have bare pipes that can get quite cold from propane expansion. There are other potential safety hazards that are not covered here.

\section{CONCLUDING COMMENTS}

This report is not complete in its coverage of hydrogen safety. It is hoped that some of the information given here is useful for designing hydrogen devices that are safe. The author has purposefully omitted direct reference to the various codes that apply to hydrogen safety or the safety of methane and propane. The codes change frequently and they vary by country. The author encourages those who design a liquid-hydrogen system to translate the applicable codes into direct engineering criteria that apply to the device being built. Safety systems should not be connected to a computer. The safety system should stand by itself.

A hydrogen safety review committee should be reviewing the engineering design, not bureaucratic paperwork. Paperwork does not make a device safe; only quality engineering can do that. A safety review should never be rushed. Time should be taken to make sure that those who do the safety review fully understand the device being reviewed.

\section{ACKNOWLEDGEMENTS}

This work was performed at the Lawrence Berkeley National Laboratory with the support of the Office of High Energy Physics, United States Department of Energy under DOE contract DE-AC02-05CH11231. DOE funding for the US Neutrino Factory and Muon Collider Collaboration is also gratefully acknowledged.

\section{REFERENCES}

1. Handbook of Chemistry and Physics 36, pp 1761 to 1763 Chemical Rubber Publishing Company, Cleveland OH, (1955)

2. Handbook of Chemistry and Physics 58, p B-438, CRC Press Inc, Cleveland OH, (1977)

3. V. D Arp and R. D. McCarthy, "Thermophysical Properties of Helium-4 from 0.8 to $1500 \mathrm{~K}$ with Pressures to $2000 \mathrm{MPa}, "$ NIST Technical Note 1334, (1989)

4. Kaye, S. and Murray, R. T., "High Altitude Explosion Properties of the Hydrogen-Oxygen System in Vented Tanks," Advances in Cryogenic Engineering 13, p 545, Plenum Press, New York NY, (1967)

5. Johnson, H. H. and Kumnick, A. J., "Hydrogen and the Integrity of Structural Alloys" Hydrogen Energy, Plenum Press, New York NY, (1975)

6. Brentari, E. G. and Smith, R. V., "Nucleate and Film Pool Boiling Design Correlations for $\mathrm{O}_{2}, \mathrm{~N}_{2}, \mathrm{H}_{2}$, and He," Advances in Cryogenic Engineering 10B, p 325, Plenum Press, New York NY. (1964)

7. Yang, S. Q. and Green M. A., "The Effect of a Hydrogen Spill inside of a $300 \mathrm{~K}$ Vacuum Vessel on MICE Absorber Hydrogen Safety," Oxford University Physics Department Engineering Note 1, MICE Note 100, http://hep04.phys.itt.edu/cooldemo, (March 2004)

8. Sciance, C. T. et al, "Pool Boiling of Methane between Atmospheric Pressure and the Critical Pressure," Advances in Cryogenic Engineering 12, p 395, Plenum Press New York NY, (1966)

9. "Spark Ignition Parameters for Cryogenic Hydrogen in Oxygen-Nitrogen Mixtures," Advances in Cryogenic Engineering 10A, p 265, Plenum Press, New York NY, (1964)

10. Cassutt, L. H. et al, "Electrostatic Hazard Associated with the Transfer and Storage of Liquid Hydrogen," Advances in Cryogenic Engineering 7, p 327, Plenum Press, New York NY, (1961) 


\section{DISCLAIMER}

This document was prepared as an account of work sponsored by the United States Government.

While this document is believed to contain correct information, neither the United States Government nor any agency thereof, nor The Regents of the University of California, nor any of their employees, makes any warranty, express or implied, or assumes any legal responsibility for the accuracy, completeness, or usefulness of any information, apparatus, product, or process disclosed, or represents that its use would not infringe privately owned rights. Reference herein to any specific commercial product, process, or service by its trade name, trademark, manufacturer, or otherwise, does not necessarily constitute or imply its endorsement, recommendation, or favoring by the United States Government or any agency thereof, or The Regents of the University of California. The views and opinions of authors expressed herein do not necessarily state or reflect those of the United States Government or any agency thereof, or The Regents of the University of California. 